\title{
The spawning aplication of Koi (Cyprinus carpio) using semi-natural method in Desa
} Perbarakan, Deli Serdang Regency

\author{
Desrita ${ }^{1 *}$, Vindy Rilani Manurung ${ }^{1}$, Rizky Febriansyah Siregar ${ }^{1}$, Rusdi Leidonald ${ }^{1}$, \\ Amanatul Fadhilah ${ }^{1}$, Astrid Fauzia Dewinta ${ }^{1}$ \\ ${ }^{1}$ Program Studi Manajemen Sumberdaya Perairan, Fakultas Pertanian \\ Universitas Sumatera Utara \\ *Email: desrita@usu.ac.id*
}

\begin{abstract}
Based on statistical analysis from Dinas Kelautan Perikanan, Deli Serdang Regency in 2018, The capacity for freshwater aquaculture output was recorded at 1328.9 tons / year with a land area of 65.9 ha , which is a problem for the aquaculture community with the decreasing quantity of seed production, limited infrastructure and development management which is still conventional in Desa Perbarakan, Deli Serdang Regency, therefore it is important to implement the required application of science and technology, namely the implementation of semi-natural methods of spawning techniques of koi fish (Cyprinus carpio). Counseling, seminars and practices are the methods of tasks carried out. Extension activities were carried out by illustrating the conceptual awareness of the development of koi fish spawning strategies, the distribution of leaflets, the application of recognition technology, as well as tools and resources, including the dose of gonadotropin hormone $(\mathrm{GnH})$ in broodfish and fish anaesthetic techniques. For female fish, the injected hormone level is $0.5 \mathrm{ml} / \mathrm{kg}$ and $0.1 \mathrm{ml} /$ $\mathrm{kg}$ for male fish. The weight of the female fish is $1 \mathrm{~kg}$ tancho sanke doitsu, $0.5 \mathrm{ml} / \mathrm{gr}$, and the weight of the male fish is $1 \mathrm{~kg}$. At a dose of $0.1 \mathrm{ml} / \mathrm{gr}$ and $900 \mathrm{~g}$ of shiro, kohaku at a level of $0.09 \mathrm{ml} / \mathrm{gr}$. The result is that the number of eggs is estimated at 10,000, and then the eggs hatch within 2-4 days. Boiled egg yolks are fed to the eggs which hatch into the larvae, then the larvae are transferred to the nursery pon after 10 days of age.
\end{abstract}

Keyword: koi fish, spawning, semi-natural method

\begin{abstract}
Abstrak
Berdasarkan data statistik Dinas Kelautan Kabupaten Deli Serdang tahun 2018, potensi produksi perikanan budidaya ikan air tawar tercatat 1328,9 ton/tahun dengan luas area lahan 65,9 ha, yang menjadi permasalahan kelompok pembudidaya semakin menurunnya kuantitas produksi benih, keterbatasan sarana prasarana dan pengembangan manajemen IPTEK yang masih tradisional di Desa Perbarakan, Kabupaten Deli Serdang, sehingga perlu mengenalkan penerapan IPTEK yang dinilai tepat yaitu mengenalkan aplikasi teknik pemijahan ikan koi (Cyprinus carpio) metode semi alami. Metode kegiatan yang dilakukan adalah penyuluhan, workshop dan praktik. Kegiatan penyuluhan dilakukan dengan menjelaskan pengetahuan konsep pengembangan teknik pemijahan ikan koi beserta pembagian leaftlet, selanjutnya penerapan teknologi pengenalan serta perisapan alat dan bahan, yaitu dosis pemberian hormon Gonadotropin $(\mathrm{GnH})$ pada induk ikan dan teknik pembiusan ikan. Dosis hormon yang disuntikkan dosis $0,5 \mathrm{ml} / \mathrm{kg}$ untuk induk betina dan $0,1 \mathrm{ml} / \mathrm{kg}$ untuk induk jantan., didapatkan bobot ikan betina $1 \mathrm{~kg}$ jenis tancho sanke doitsu dosis $0,5 \mathrm{ml} / \mathrm{gr}$, bobot ikan jantan $1 \mathrm{~kg}$ jenis kohaku dosis $0,1 \mathrm{ml} / \mathrm{gr}$ dan $900 \mathrm{gr}$ jenis shiro dosis $0,09 \mathrm{ml} / \mathrm{gr}$. Hasilnya jumlah telur diperkirakan 10.000 selanjutnya kurun waktu 2-4 hari telur tersebut menetas. Telur yang menetas menjadi larva, diberi makanan kuning telur rebus, selanjutnya setelah umur 10 hari, selanjutnya larva dipindahkan ke kolam pendederan.
\end{abstract}

Kata Kunci: ikan koi, pemijahan, metode semi alami 


\section{PENDAHULUAN}

Komoditas ikan hias air tawar yang masih menjadi primadona di pasar nasional maupun internasional adalah ikan koi (Cyprinus carpio. Warna pada ikan koi menjadikan daya tarik masyarakat, harga jual ikan koi semakin meningkat sejalan dengan intensitas warna kulit yang merupakan kriteria kualitas penting dari ikan koi (Putri and Dewi, 2016) sehingga perlu para pembudidaya mempertahankan warna ikan hias tersebut (Andriani et al., 2019). Nilai jual koi di Indonesia membuat pemerintah ikut serta dalam mengembangkan daerah-daerah khusus menjadi sentral penghasil koi melalui konsep minapolitan (Kusrini et al., 2015). Berdasarkan data statistik Dinas Kelautan Kabupaten Deli Serdang tahun 2018, produksi perikanan budidaya ikan air tawar tercatat 1328,9 ton/tahun dengan luas area lahan 65,9 ha. Data ini menunjukkan adanya potensi sumberdaya perikanan khususnya dibidang perikanan budidaya.

Saat ini kelompok pembudidaya masih menerapkan proses pemijahan ikan koi sistem tradisional dengan mempertahankan sistem pemijahan alami yaitu pemijahan ikan tanpa campur tangan manusia, terjadi secara alamiah tanpa perlakuan atau pemberian hormon (Gusrina, 2014). mengeluh semakin menurunnya kuantitas produksi benih. Ketersediaan benih tidak hanya dalam jumlah namun juga kualitas benih itu sendiri untuk menentukan pertumbuhan ikan (Yuatiati et al., 2015). Hal ini disebabkan oleh keterbatasan modal, sarana prasarana dan pengembangan manajemen IPTEK yang menjadi permasalahan kelompok pembudidaya saat ini. Di desa Perbarakan, Kabupaten Deli Serdang Provinsi Sumatera Utara merupakan desa yang memiliki pembudidaya ikan hias air tawar khususnya budidaya ikan koi (Cyprinus carpio). Saat ini kegiatan kelompok terfokus pada pemijahan ikan koi metode alami yang masih tradisional sehingga perlu mengenalkan penerapan iptek yang dinilai tepat. Tujuan kegiatan aplikasi ini sebagai referensi untuk meningkatkan ilmu pengetahuan dibidang perikanan budidaya dan mengenalkan aplikasi teknik pemijahan ikan koi (Cyprinus carpio) metode semi alami di desa Perbarakan, Kabupaten Deli Serdang, Sumatera Utara.

\section{METODE PELAKSANAAN}

Kegiatan ini telah dilakukan pada bulan Agustus sampai Oktober 2020, selanjutnya metode pelaksanaan kegiatan terbagi 3 tahap yaitu, kegiatan penyuluhan, kegiatan workshop dan kegiatan praktik dilakukan di Desa Perbarakan, Kabupaten Deli Serdang, Sumatera Utara dengan melibatkan kelompok pembudidaya ikan koi di desa tersebut, diagram alir dapat dilihat pada Gambar 1. 
Desrita et al. The spawning aplication of Koi (Cyprinus carpio) using semi-natural

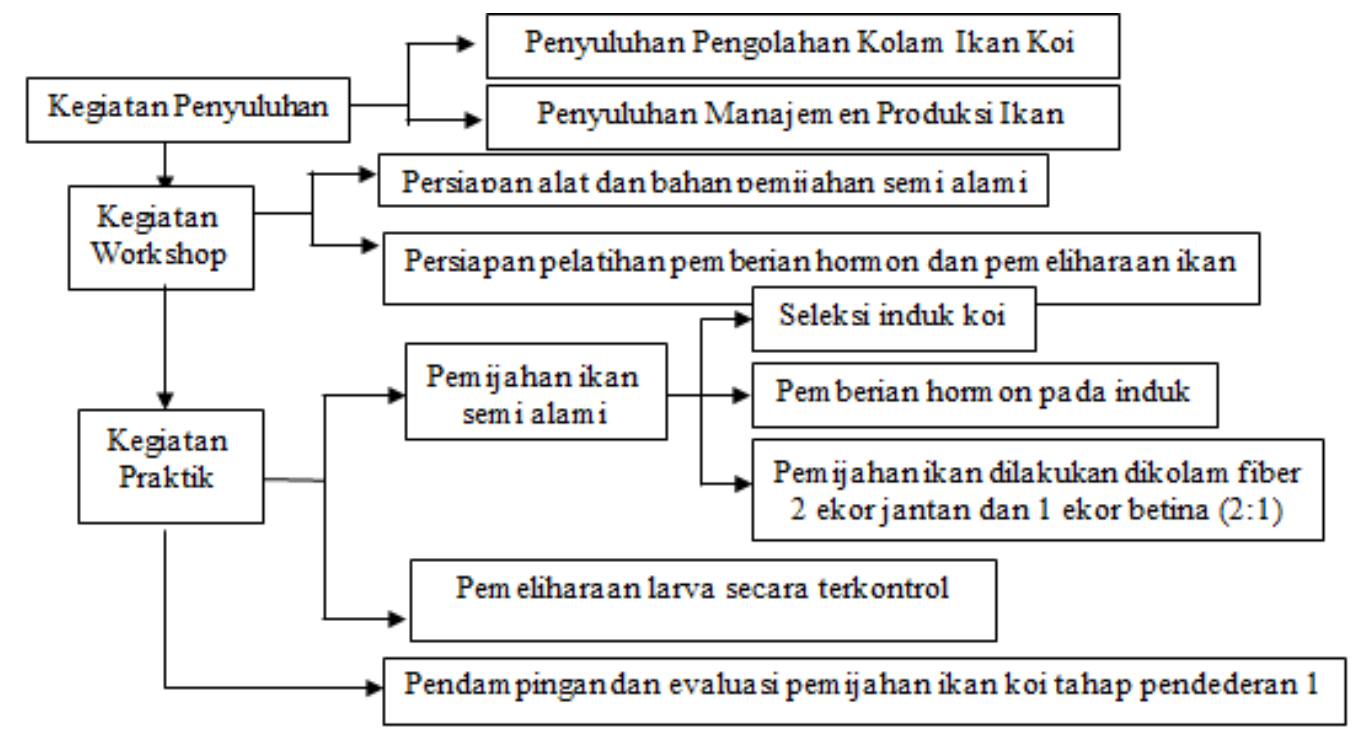

Gambar 1. Diagram Alir Prosedur Pelaksanaan

\section{HASIL DAN PEMBAHASAN}

\section{Kegiatan Penyuluhan}

Kegiatan penyuluhan melibatkan masyarakat dan kelompok pembudidaya ikan hias koi di Desa Perbarakan, dengan membagikan leaftlet, selanjutnya menjelaskan pengetahuan tentang konsep pengembangan teknik pemijahan ikan koi (Cyprinus carpio) dengan metode semi alami, menggambarkan konsep aplikasi manajemen pemberian dosis hormon Gonadotropin, manajemen kualitas air dan pemeliharaan di kolam sehingga masyarakat dan mitra kelompok pembudidaya ikan koi dapat mengoptimalkan potensi usaha dalam segi kuantitas produksi budidaya ikan koi. Kegiatan penyuluhan dapat dilihat pada Gambar 2.

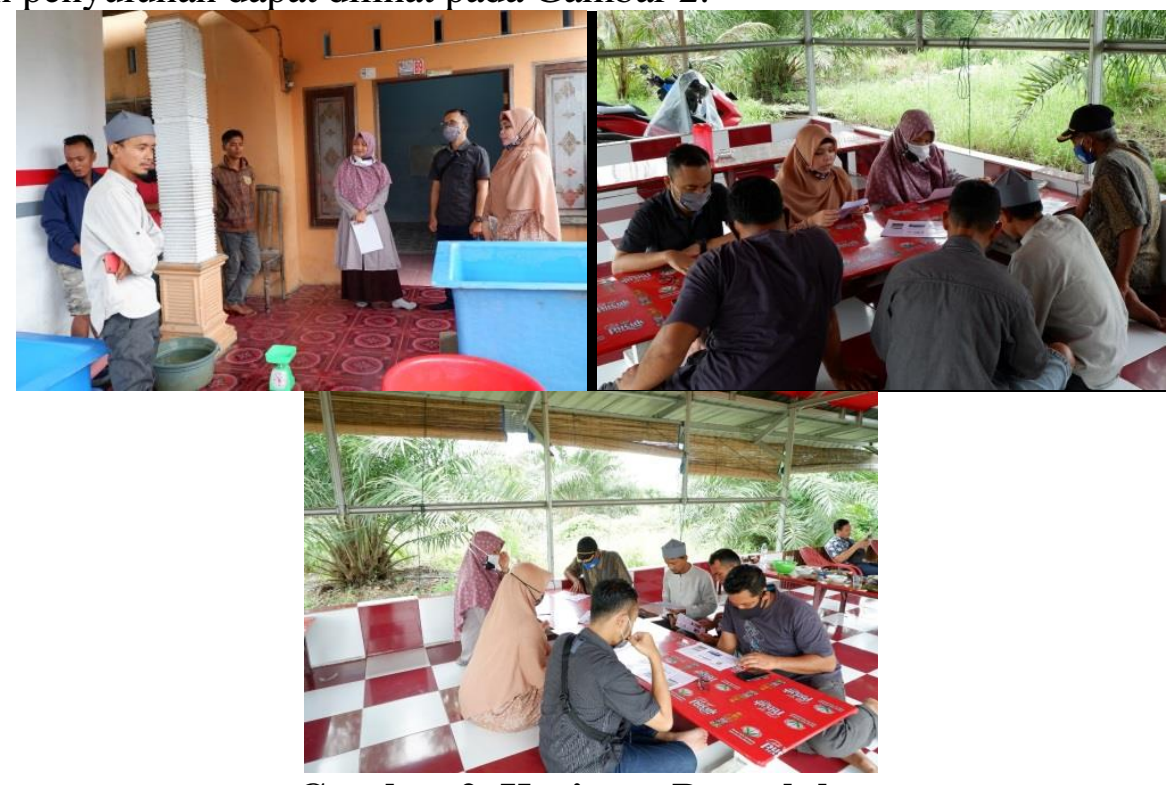

Gambar 2. Kegiatan Penyuluhan 


\section{Kegiatan Workshop}

Pelatihan terhadap penerapan teknologi dan manajemen disertai dengan pengenalan serta perisapan alat dan bahan, memberi pemahaman dosis pemberian hormon Gonadotropin $(\mathrm{GnH})$ pada induk ikan dan teknik pembiusan ikan. Kegiatan workshop dapat dilihat pada Gambar 3.

Sebagai bentuk mendukung kegiatan ini dibutuhkan alat dan bahan untuk kegiatan pemijahan semi alami yaitu, alat yang digunakan 1 unit kolam fiber, 1 unit kolam beton beserta satu set kelengkapan untuk kebutuhan wadah pemijahan berupa blower, pompa, aerator, baskom, spuit $1 \mathrm{cc}$ dan handuk basah. Bahan yang digunakan induk ikan koi 2 jantan dan 1 betina, hormon Gonadotropin $(\mathrm{GnH})$ dan kakaban (sebagai tempat peletakan telur).

Pemijahan semi alami yang dilakukan adalah mengawinkan induk jantan dan betina perbandingan 2:1, dengan menggunakan bantuan hormon Gonadotropin dosis $0,5 \mathrm{ml} / \mathrm{kg}$ untuk induk betina dan $0,1 \mathrm{ml} / \mathrm{kg}$ untuk induk jantan.

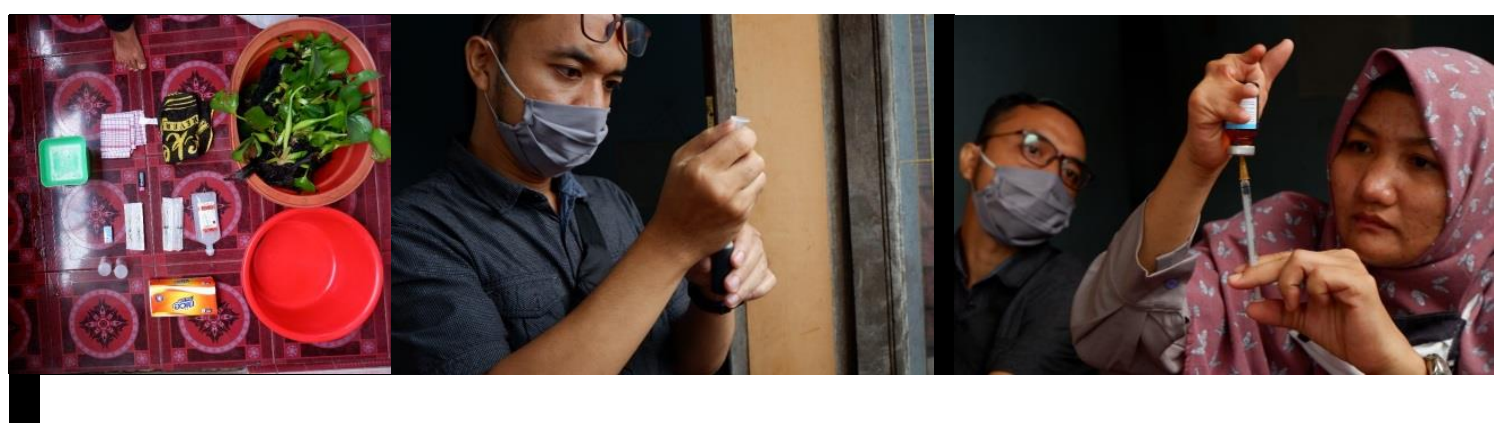

\section{Kegiatan Praktik}

\section{Gambar 3. Kegiatan Workshop}

Persiapan alat dan bahan telah dilakukan, kemudian hasil seleksi induk ikan koi menggunakan 3 ekor ikan yaitu 1 ekor ikan betina jenis tancho sanke doitsu, 1 ekor jantan jenis kohaku dan 1 ekor jantan jenis shiro. Tujuan seleksi yaitu menyiapkan induk yang matang gonad dan siap dipijahkan, diharapkan nantinya menghasilkan keturunan yang diinginkan (Kusrini et al., 2015).

Selanjutnya untuk mendapatkan dosis hormon yang akan disuntikan dosis $0,5 \mathrm{ml} / \mathrm{kg}$ untuk induk betina dan $0,1 \mathrm{ml} / \mathrm{kg}$ untuk induk jantan. Ikan perlu ditimbang terlebih dahulu, didapatkan bobot ikan betina $1 \mathrm{~kg}$ jenis tancho sanke doitsu dosis $0,5 \mathrm{ml} / \mathrm{gr}$, bobot ikan jantan $1 \mathrm{~kg}$ jenis kohaku dosis $0,1 \mathrm{ml} / \mathrm{gr}$ dan $900 \mathrm{gr}$ jenis shiro dosis $0,09 \mathrm{ml} / \mathrm{gr}$.

Langkah selanjutnya pembiusan induk jantan dan betina (dosis minyak cengkeh 0,3 $\mathrm{ml} / 1$ liter air). Setelah pingsan, ikan dibungkus dengan kain basah lalu siap disuntik hormon ovaprim pada pukul 10.00 WIB sesuai dosis yang ditentukan, kemudian ikan dilepaskan kembali ke kolam, dengan tujuan menunggu waktu ovulasi 7-9 jam sampai ikan memijah. Menurut Kusrini, et al (2015) pemijahan ikan koi dengan cara menstimulasi dengan hormone gonadotropin dengan menggunakan dosis $0,5 \mathrm{ml} / \mathrm{kg}$ pada induk betina dan $0,3 \mathrm{mg} / \mathrm{kg}$ pada induk jantan, kemudian penyuntikan dilakukan sore hari, proses penyuntikan dapat dilihat pada Gambar 4. 


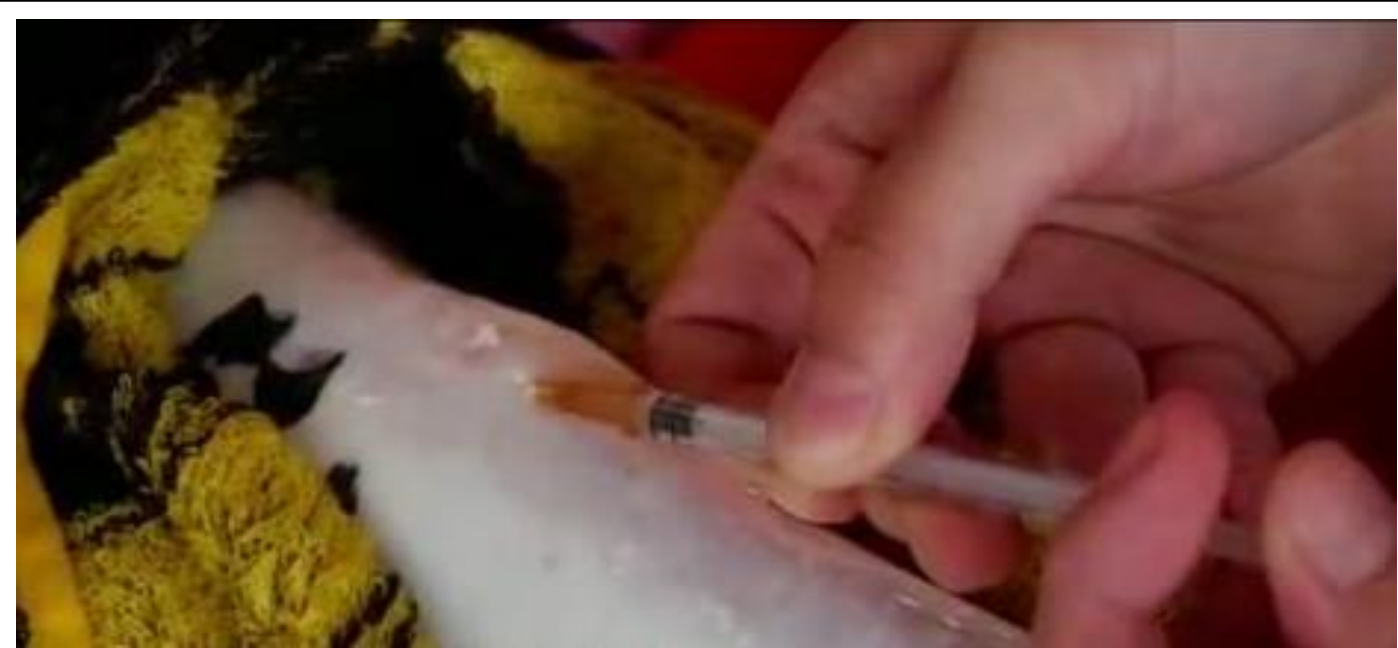

Gambar 4. Penyuntikan Hormon Pada Ikan Koi

Penyuntikan dilakukan disamping kiri atau kanan sirip punggung secara intramuscular yaitu langsung pada daging ikan posisi $45^{\circ}$ secara perlahan. Setelah disuntik dilepas ke kolam pemijahan yang berisi eceng gondok, langkah memasukkan induk koi dalam kolam pemijahan perlu diperhatikan mendahulukan induk ikan betina kemudian menyusul induk ikan jantan (Telaumbanua et al., 2020). Selanjutnya tunggu sampai ikan berovulasi dan fertilisasi. Setelah ikan berovulasi segera pisahkan induk ikan koi, untuk mencegah induk koi memakan telur-telurnya.

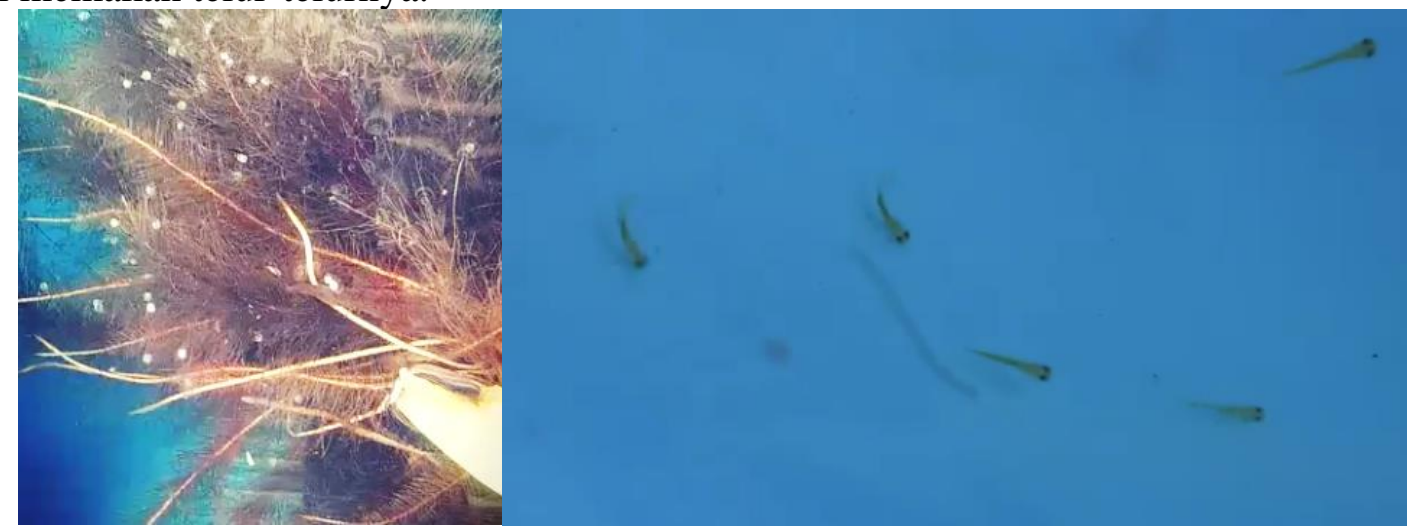

Gambar 5. Telur dan Larva Ikan Koi Yang Menetas

Telur yang telah dipisahkan kemudian di biarkan terlebih dahulu menempel pada tanaman eceng gondok, jumlah telur diperkirakan 10.000 selanjutnya kurun waktu 2-4 hari telur-telur tersebut menetas, dapat dilihat pada Gambar 5. Fekunditas ikan dapat dipengaruhi oleh ukuran, umur, spesies ikan, dan pengaruh lingkungan, faktor berat induk juga dapat mempengaruhi fekunditas atau jumlah telur (Ishaqi dan Sari., 2019). Telur yang telah menetas akan menjadi larva, selanjutnya perawatan larva diberi makanan kuning telur rebus, setelah umur 10 hari, selanjutnya larva dipindahkan ke kolam pendederan.

\section{KESIMPULAN}

Terbentuknya kelompok budidaya ikan hias di Desa Perbarakan, Kecamatan Pagar Merbau, Kabupaten Deli Serdang dikarenakan metode ini tidak hanya terbatas pada spesies ikan koi saja melainkan dapat diterapkan oleh kelompok pembudidaya komoditas 
ikan jenis lain. Kegiatan ini menyadarkan kelompok budidaya untuk mempercepat kematangan gonad ikan bisa dilakukan dengan bantuan hormon sehingga dapat menghemat waktu proses pemijahan dan tingkat keberhasilan lebih tinggi dibandingkan dengan teknik pemijahan alami yang masih tradisional.

\section{UCAPAN TERIMAKASIH}

Tim pelaksana mengucapkan terima kasih kepada LPPM USU yang telah membiayai kegiatan ini melalui dana Non PNBP USU dengan Surat Perjanjian Pelaksanaan Penugasan Pengabdian kepada Masyarakat Nomor: 695/UN5.2.3.2.1/PPM/2020, Tanggal 24 Juli- 30 November 2020. Tim juga mengucapkan terima kasih kepada segala pihak yang terlibat dalam kegiatan Pengabdian kepada Masyarakat.

\section{DAFTAR PUSTAKA}

Andriani Y, Asri P.W, Rusky I.P., dan Irfan Z. 2019. Peningkatan Kualitas Ikan Koi (Cyprinus carpio) Di Kelompok PBC Fish Farm Di Kecamatan Cisaat, Sukabumi. Jurnal Ilmiah Pengabdian Masyarakat. Vol 5 (1): 33-38.

Gusrina. 2014. Genetika dan Reproduksi Ikan. Deepublish. Yogyakarta. $259 \mathrm{hlm}$.

Ishaqi, A.M.A dan Sari, P.D.W., 2019. Pemijahan Ikan Koi (Cyprinus Carpio) dengan Metode Semi Buatan: Pengamatan Nilai Fekunditas, Derajat Pembuahan Telur dan Daya Tetas Telur. Jurnal Perikanan dan Kelautan. 9 (2). 216-224.

Kusrini, Sawung C dan Anjang B.P. 2015. Pengembangan Budidaya Ikan Hias Koi (Cyprinus carpio) Lokal Di Balai Penelitian Dan Pengembangan Budidaya Ikan Hias Depok. Jurnal Media Akuakultur. 10( 2): 71-78.

Putri. F.P and Dewi. N.N. 2019. Growth monitoring of koi fish (Cyprinus carpio) in natural hatchery techniques in Umbulan, Pasuruan, East Java. IOP Conf. Series: Earth and Environmental Science 236. 1755-1315.

Telaumbanua, E.I., Sinaga, I dan Simamora, F. 2020. Efektifitas Penggunaan Ovaprim Dengan Dosis Yang Berbeda Pada Pemijahan Ikan Mas (Cyprinus Carpio). Jurnal Penelitian Terapan Perikanan dan Kelautan. 2 (1) 32-40.

Yuatiati, A., Herawati, T dan Nurhayati, A. 2015. Diseminasi Penggunaan Ovaprim Untuk Mempercepat Pemijahan Ikan Mas Di Desa Sukamahi Dan Sukagalih Kecamatan Sukaratu Kabupaten Tasikmalaya Provinsi Jawa Barat. Jurnal Aplikasi Ipteks untuk Masyarakat. 4 (2). 1-3. 